\title{
Improvement of Short-Circuit Current Density in Dye-Sensitized Solar Cells Using Sputtered Nanocolumnar $\mathrm{TiO}_{2}$ Compact Layer
}

\author{
Lung-Chien Chen, Cheng-Chiang Chen, and Bo-Shiang Tseng \\ Department of Electro-optical Engineering, National Taipei University of Technology, 1, sec.3, Chung-Hsiao E. Rd., Taipei 106, Taiwan \\ Correspondence should be addressed to Lung-Chien Chen, ocean@ntut.edu.tw
}

Received 23 August 2010; Revised 15 November 2010; Accepted 19 November 2010

Academic Editor: Shijun Liao

Copyright () 2010 Lung-Chien Chen et al. This is an open access article distributed under the Creative Commons Attribution License, which permits unrestricted use, distribution, and reproduction in any medium, provided the original work is properly cited.

\begin{abstract}
The effect of a nanocolumnar $\mathrm{TiO}_{2}$ compact layer in dye-sensitized solar cells (DSSCs) was examined. Such a compact layer was sputtered on a glass substrate with an indium tin oxide (ITO) film using $\mathrm{TiO}_{2}$ powder as the raw material, with a thickness of $\sim 100 \mathrm{~nm}$. The compact layer improved the short-circuit current density and the efficiency of conversion of solar energy to electricity by the DSSC by $53.37 \%$ and $59.34 \%$, yielding values of $27.33 \mathrm{~mA} / \mathrm{cm}^{2}$ and $9.21 \%$, respectively. The performance was attributed to the effective electron pathways in the $\mathrm{TiO}_{2}$ compact layer, which reduced the back reaction by preventing direct contact between the redox electrolyte and the conductive substrate.
\end{abstract}

\section{Introduction}

Dye-sensitized solar cells (DSSCs) are of particular interest in the field of solar energy, because of their low cost, simplicity of fabrication, and high solar energy conversion efficiency [1-5]. They have a basic structure that comprises two conductive substrates (another is coated catalyzer, for example, platinum), an absorbing layer of semiconductor materials, dye molecules, and a redox electrolyte. The principle of operation of DSSCs is that electrons are injected from the photoexcited dye into the conductive band of the semiconductor and forward flows to an external loop under illumination, while the electrolyte reduces the oxidized dye and transports the positive charges to the counter electrode. Extensive research has been performed to improve each component of DSSCs.

Gold nanoparticles (GNPs) have been used in solar cells because of their particular optical and electrical properties. They reportedly increase the generation of charge carriers, photocurrent, and efficiency of conversion of solar energy in DSSCs [6-8]. Several materials have been employed in the compact layer, or blocking layer; they include $\mathrm{TiO}_{2}$ [9-11], $\mathrm{Nb}_{2} \mathrm{O}_{5}$ [12], $\mathrm{ZnO}$ [13], $\mathrm{CaCO}_{3}$ [14], and $\mathrm{BaCO}_{3}$ [15], which reduce the area of contact between the conductive substrate and the redox electrolyte. Among them, $\mathrm{TiO}_{2}$ is commonly preferred because of its favorable antichemical and antiphoto corrosion abilities. The introduction of the compact layer between the conductive substrate and the porous films may improve the adherence between them and the transfer of electrons by increasing the number of electron pathways.

In this study, short-circuit current density is increased by introducing a compact layer to improve the performance of DSSCs. The photovoltaic characteristics of DSSC with and without a nanocolumnar $\mathrm{TiO}_{2}$ compact layer were investigated by making spectral response and illuminated current density-voltage $(J-V)$ measurements.

\section{Experiment}

Colloidal $\mathrm{TiO}_{2}$ was prepared from $6 \mathrm{~g}$ nanocrystalline powder (Degussa, P25 titanium oxide, Japan), $0.1 \mathrm{~mL}$ of TritionX-100, $0.2 \mathrm{~mL}$ of acetylacetone, and $3 \mathrm{~mL}$ of aqueous GNPs in $7 \mathrm{~mL}$ deionized water, which were stirred together for 14 hrs. Subsequently, the mixture was spin-coated on indium tin oxide (ITO) glass substrate to a thickness of around $15 \mu \mathrm{m}$, and a $0.3 \times 0.3$ active area was defined. Thereafter, the photoelectrode was immersed in a $3 \times$ $10^{-4} \mathrm{M}$ solution of dye (cis-bis(isothiocyanato) bis $\left(2,2^{\prime}-\right.$ bipyridyl-4,4'-dicarboxylato)-ruthenium(II) $\left(\mathrm{N}_{3}\right)$ in ethanol 


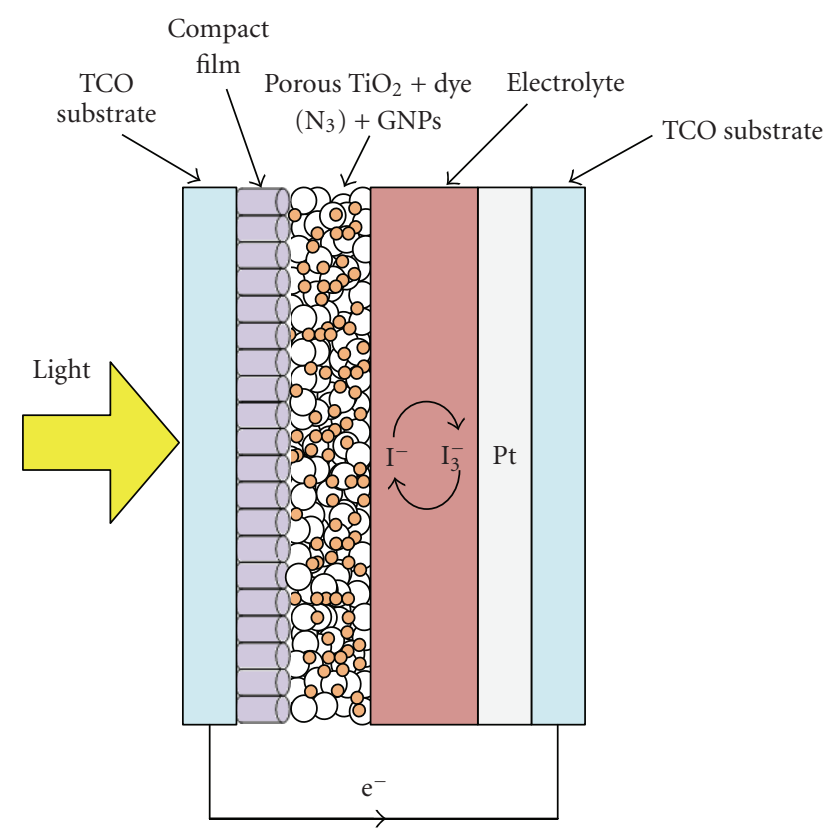

FIGURE 1: Schematic cross section of the DSSCs with nanocolumnar $\mathrm{TiO}_{2}$ compact layer.

for $24 \mathrm{hrs}$, before being sintered at $450^{\circ} \mathrm{C}$ for $30 \mathrm{~min}$, to increase its anatase content (anatase : rutile $=85: 15$ ) [16]. The compact layer was formed on an ITO glass substrate by sputtering the target using $\mathrm{P} 25 \mathrm{TiO}_{2}$ powder as a raw material. The electrolyte was composed of $0.05 \mathrm{M}$ iodide and $0.5 \mathrm{M}$ lithium iodide with and without $0.5 \mathrm{M}$ 4-tertbutylpyridine (TBP) in propylene carbonate. Then, a $100 \mathrm{~nm}$ thick layer of platinum was sputtered onto ITO substrate as a counter electrode. Cells were fabricated by placing sealing films (SX1170-60, SOLARONIX) between the two electrodes, and just leaving two via-holes for injection electrolyte. The sealing process was carried out on a hot plate at $100^{\circ} \mathrm{C}$ for $3 \mathrm{~min}$. Then, the electrolyte was injected into the space between the two electrodes through the via-holes. Finally, the via-holes were sealed using the epoxy with low vapor transmission rate. Figure 1 schematically depicts the complete structure.

A field emission scanning electron microscope (FESEM) (LEO 1530) was adopted to examine the cross-section and surface morphology of the cells. The $J-V$ characteristics were measured using a Keithley 2420 programmable source meter under irradiation by a $1000 \mathrm{~W}$ xenon lamp. The incident photon to electron conversion efficiency (IPCE) was measured using a spectrometer (DM-201, DONGWOO OPTRON) also under illumination by the $1000 \mathrm{~W}$ xenon lamp. Finally, the irradiation power density on the surface of the sample was calibrated as $100 \mathrm{~mW} / \mathrm{cm} 2$.

\section{Results and Discussion}

Figures 2(a) and 2(b) present the cross-sectional and surface SEM images of the $\mathrm{TiO}_{2}$ compact layer on ITO glass substrate. The mean size of the porous $\mathrm{TiO}_{2}$ particles and the size of the nanocolumns of the $100 \mathrm{~nm}$ thick $\mathrm{TiO}_{2}$ compact layer, were about $12 \mathrm{~nm}$. The diameter of the sputtered $\mathrm{TiO}_{2}$ compact layer had a diameter similar to that of the porous $\mathrm{TiO}_{2}$ film that absorbed the dye molecules. Accordingly, the porous $\mathrm{TiO}_{2}$ film formed a superior contact with the nanocolumnar $\mathrm{TiO}_{2}$ compact layer and the electrolyte could not come into direct contact with the ITO substrate. The back transfer of electrons was thus reduced.

Figure 3 shows a typical XRD pattern of a $\mathrm{TiO}_{2}$ compact layer that is deposited on ITO glass substrate by sputtering. Two dominant anatase diffraction peaks, $(101)\left(2 \theta=25.28^{\circ}\right)$ and $(004)\left(2 \theta=37.73^{\circ}\right)$, are observed. The results are consistent with the SEM image of nanoporous $\mathrm{TiO}_{2}$ in Figure 2(a). Anatase-based $\mathrm{TiO}_{2}$ has been regarded as the best semiconductor oxide for DSSCs, because an anatase film has a larger surface area per unit volume than a rutile film, and so is better able to absorb dye, has a longer electron diffusion coefficient, and has a shorter electron transit time $[3,17,18]$.

Figure 4 plots the $J-V$ characteristics of DSSCs with and without a $\mathrm{TiO}_{2}$ compact layer that was injected with different electrolytes. Table 1 presents the characteristic parameters of these DSSCs. The cell has an active area of $0.3 \times 0.3 \mathrm{~cm}^{2}$ and no antireflective coating. The short-circuit current density and the efficiency of conversion of solar energy to electricity of traditional DSSCs with a $\mathrm{TiO}_{2}$ compact layer were improved by $53.37 \%$ and $59.34 \%$, respectively. Therefore, the improvement in the overall performance of DSSCs was due to the introduction of a nanocolumnar $\mathrm{TiO}_{2}$ compact layer.

The increase in the short-circuit current density and the number of electrons that could reach the ITO substrate was attributed to the presence of effectively continuous electron pathways, which reduced the recombination of electrons, between the porous $\mathrm{TiO}_{2}$ film and the ITO substrate. Furthermore, in this work, the GNPs were doped in porous $\mathrm{TiO}_{2}$ films, raising the Fermi level $[7,8]$ as a Schottky barrier, and then the exiting electrons flowed spontaneously into the $\mathrm{TiO}_{2}$ conductive band through the barrier, inhibiting the back-transfer of electrons [19]. Hence, the solar conversion efficiency of DSSCs with a compact layer was higher than that of traditional DSSCs.

Figure 5 plots the IPCE spectra obtained with and without a $\mathrm{TiO}_{2}$ compact layer. It demonstrates that the energy conversion efficiency of DSSCs with a $\mathrm{TiO}_{2}$ compact layer was overall higher than that of DSSCs without a $\mathrm{TiO}_{2}$ compact layer. In particular, the difference between the efficiency with a compact layer and that without was approximately $20 \%$. The IPCE also can be determined using the following equation $[20,21]$ :

$$
\operatorname{IPCE}(\lambda)=\operatorname{LHE}(\lambda) \cdot \varphi_{\text {inj }} \cdot \eta_{\text {coll }},
$$

where LHE denotes the light harvesting efficiency of the dye molecule; $\varphi_{\text {inj }}$ is the electron injection efficiency of the excited dye into the $\mathrm{TiO}_{2}$, and $\eta_{\text {coll }}$ is the collection efficiency of the system.

The procedures, equipment, and working environment of DSSCs were the same in all experiments: the parameters $\varphi_{\text {inj }}$ and LHE were held almost constant, so the IPCE value 


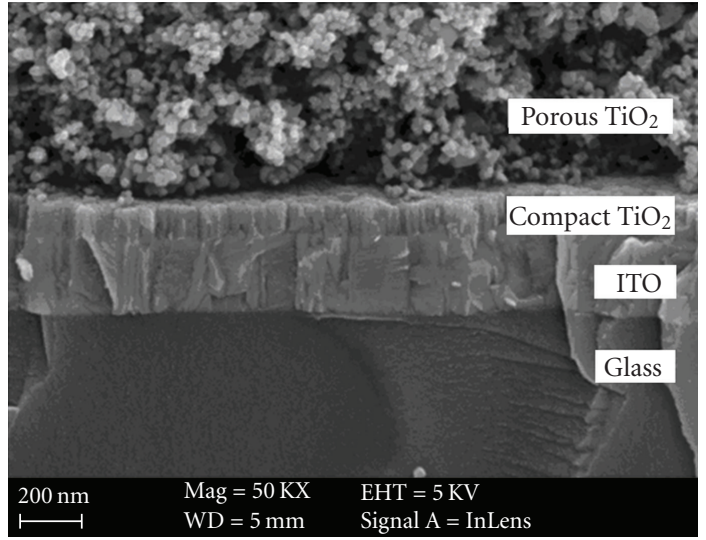

(a)

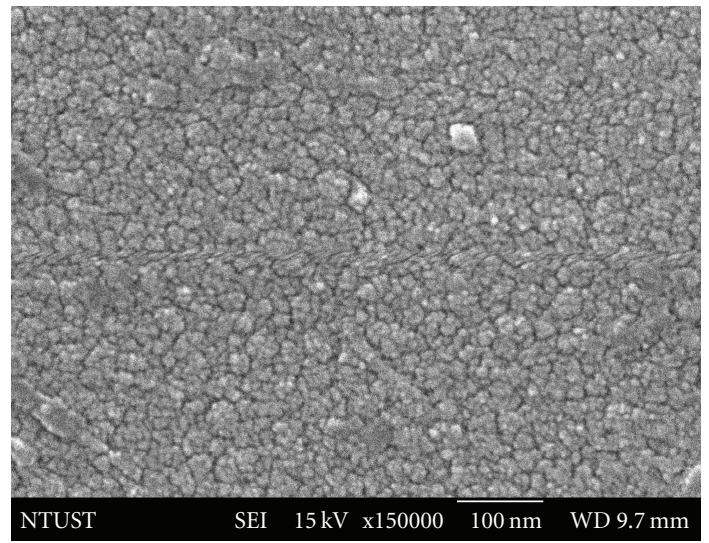

(b)

FIgURE 2: (a) The SEM cross-section image of photoanode with compact layer. (b) The SEM morphological image of TiO ${ }_{2}$ compact film.

TABLE 1: The parameters of DSSCs with and without $\mathrm{TiO}_{2}$ compact layer (CPL) at different electrolytes.

\begin{tabular}{|c|c|c|c|c|}
\hline Sample & $V_{\mathrm{oc}}(\mathrm{V})$ & $J_{\mathrm{sc}}\left(\mathrm{mA} / \mathrm{cm}^{2}\right)$ & F.F. & $\eta(\%)$ \\
\hline $\mathrm{CPL}+\mathrm{LiI}$ & 0.563 & 27.33 & 0.599 & 9.21 \\
\hline LiI & 0.526 & 17.82 & 0.617 & 5.78 \\
\hline $\mathrm{CPL}+\mathrm{LiI}+\mathrm{TBP}$ & 0.681 & 11.82 & 0.609 & 4.90 \\
\hline $\mathrm{LiI}+\mathrm{TBP}$ & 0.692 & 5.31 & 0.561 & 2.06 \\
\hline
\end{tabular}

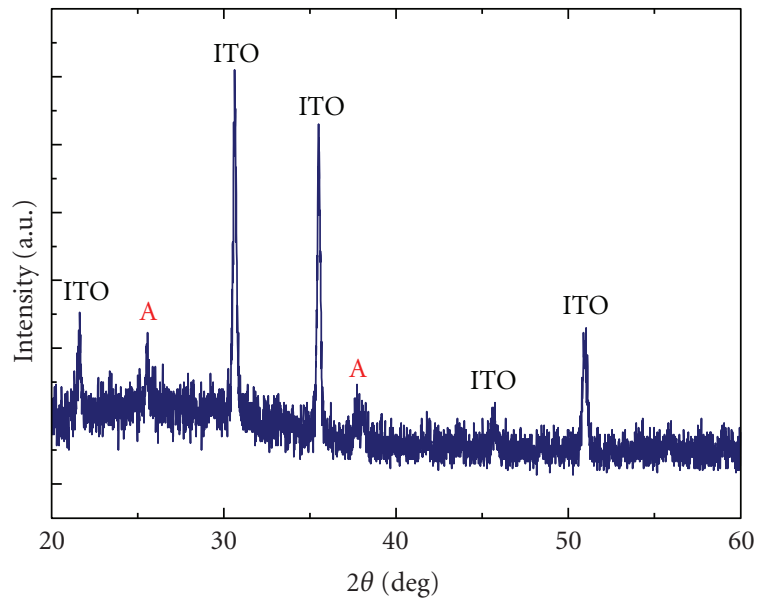

A: anatase

FIGURE 3: XRD pattern of compact layer on ITO substrate.

was thus determined by $\eta_{\text {coll }}$ according to (1). Consequently, the parameter $\eta_{\text {coll }}$ of DSSCs with a compact layer exceeded that of those without because the former contained more effective electron pathways.

\section{Conclusions}

This work discusses the improvement associated with the introduction of a nanocolumnar $\mathrm{TiO}_{2}$ compact layer between the porous $\mathrm{TiO}_{2}$ film and the conductive substrate in DSSCs. The short-circuit current density and the efficiency

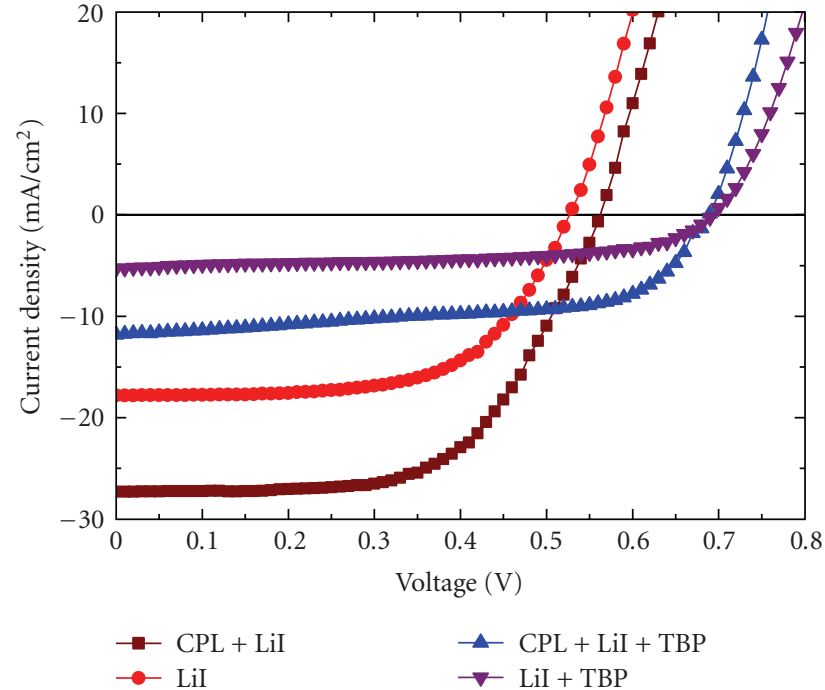

FIgUre 4: The $J-V$ characteristics of DSSCs with and without compact layer at different electrolytes.

of conversion of solar energy to electricity were thus improved by $53.37 \%$ and $59.34 \%$, respectively. The enhanced performance of DSSCs with a compact layer was attributed to the increase in contact area between porous $\mathrm{TiO}_{2}$ and the ITO substrate and the presence of effectively continuous electrons pathways in the sputtered $\mathrm{TiO}_{2}$ compact layer, which reduced back transfer by preventing direct contact between the redox electrolyte and the conductive substrate. Therefore, the short-circuit current density and efficiency 


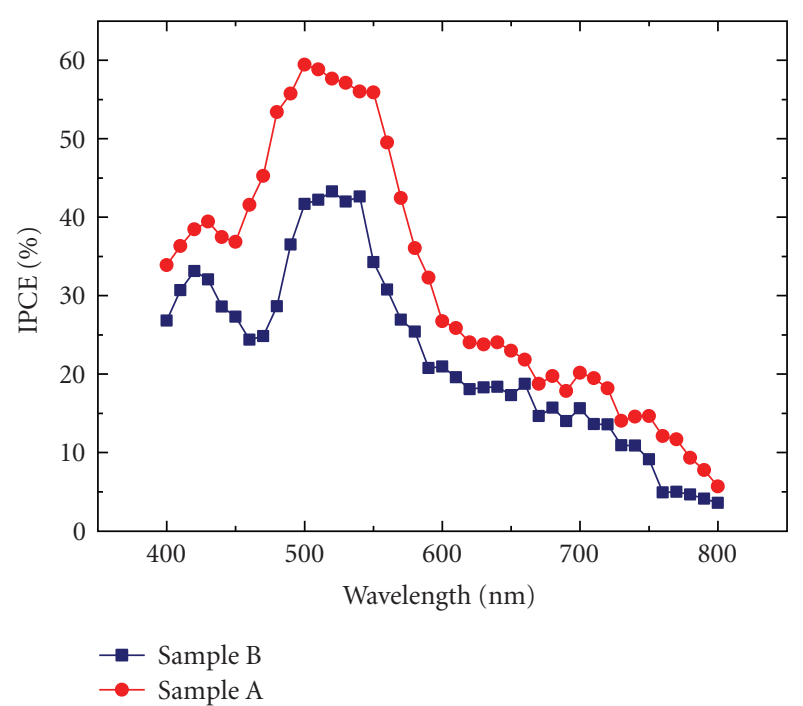

FIGURE 5: Photocurrent action spectra of DSSCs with and without compact layer.

of conversion of solar energy to electricity were increased to $27.33 \mathrm{~mA} / \mathrm{cm}^{2}$ and $9.21 \%$, respectively, under illumination by a $1000 \mathrm{~W}$ Xe lamp.

\section{Acknowledgment}

Financial support of this paper was provided by the National Science Council of the Republic of China under Contract no. NSC 98-2221-E-027-015.

\section{References}

[1] B. O’Regan and M. Grätzel, "A low-cost, high-efficiency solar cell based on dye-sensitized colloidal $\mathrm{TiO}_{2}$ films," Nature, vol. 353, no. 6346, pp. 737-740, 1991.

[2] B. O’Regan, J. Moser, M. Anderson, and M. Grätzel, "Vectorial electron injection into transparent semiconductor membranes and electric field effects on the dynamics of light-induced charge separation," Journal of Physical Chemistry, vol. 94, no. 24, pp. 8720-8726, 1990.

[3] N. G. Park, J. van de Lagemaat, and A. J. Frank, "Comparison of dye-sensitized rutile- and anatase-based $\mathrm{TiO}_{2}$ solar cells," Journal of Physical Chemistry B, vol. 104, no. 38, pp. 89898994, 2000.

[4] M. Y. Song, D. K. Kim, K. J. Ihn, S. M. Jo, and D. Y. Kim, "Electrospun $\mathrm{TiO}_{2}$ electrodes for dye-sensitized solar cells," Nanotechnology, vol. 15, no. 12, pp. 1861-1865, 2004.

[5] J. Bisquert, D. Cahen, G. Hodes, S. Rühle, and A. Zaban, "Physical chemical principles of photovoltaic conversion with nanoparticulate, mesoporous dye-sensitized solar cells," Journal of Physical Chemistry B, vol. 108, no. 24, pp. 8106-8118, 2004.

[6] C. Hägglund, M. Zäch, and B. Kasemo, "Enhanced charge carrier generation in dye sensitized solar cells by nanoparticle plasmons," Applied Physics Letters, vol. 92, no. 1, Article ID 013113, 2008.
[7] S. Barazzouk and S. Hotchandani, "Enhanced charge separation in chlorophyll a solar cell by gold nanoparticles," Journal of Applied Physics, vol. 96, no. 12, pp. 7744-7746, 2004.

[8] S. W. Tong, C. F. Zhang, C. Y. Jiang et al., "Improvement in the hole collection of polymer solar cells by utilizing gold nanoparticle buffer layer," Chemical Physics Letters, vol. 453, no. 1-3, pp. 73-76, 2008.

[9] J. N. Hart, D. Menzies, Y. B. Cheng, G. P. Simon, and L. Spiccia, " $\mathrm{TiO}_{2}$ sol-gel blocking layers for dye-sensitized solar cells," Comptes Rendus Chimie, vol. 9, no. 5-6, pp. 622-626, 2006.

[10] R. Hattori and H. Goto, "Carrier leakage blocking effect of high temperature sputtered $\mathrm{TiO}_{2}$ film on dye-sensitized mesoporous photoelectrode," Thin Solid Films, vol. 515, no. 20-21, pp. 8045-8049, 2007.

[11] K.-S. Ahn, M.-S. Kang, J.-W. Lee, and Y. S. Kang, "Effects of a surfactant-templated nanoporous $\mathrm{TiO}_{2}$ interlayer on dyesensitized solar cells," Journal of Applied Physics, vol. 101, no. 8, Article ID 084312, 2007.

[12] J. Xia, N. Masaki, K. Jiang, and S. Yanagida, "Sputtered $\mathrm{Nb}_{2} \mathrm{O}_{5}$ as a novel blocking layer at conducting glass/ $/ \mathrm{TiO}_{2}$ interfaces in dye-sensitized ionic liquid solar cells," Journal of Physical Chemistry C, vol. 111, no. 22, pp. 8092-8097, 2007.

[13] S.-J. Roh, R. S. Mane, S.-K. Min, W.-J. Lee, C. D. Lokhande, and S.-H. Han, "Achievement of $4.51 \%$ conversion efficiency using $\mathrm{ZnO}$ recombination barrier layer in $\mathrm{TiO}_{2}$ based dyesensitized solar cells," Applied Physics Letters, vol. 89, no. 25, Article ID 253512, 2006.

[14] Z. S. Wang, M. Yanagida, K. Sayama, and H. Sugihara, "Electronic-insulating coating of $\mathrm{CaCO}_{3}$ on $\mathrm{TiO}_{2}$ electrode in dye-sensitized solar cells: improvement of electron lifetime and efficiency," Chemistry of Materials, vol. 18, no. 12, pp. 2912-2916, 2006.

[15] X. Wu, L. Wang, F. Luo, B. Ma, C. Zhan, and Y. Qiu, " $\mathrm{BaCO}_{3}$ modification of $\mathrm{TiO}_{2}$ electrodes in quasi-solid-state dyesensitized solar cells: performance improvement and possible mechanism," Journal of Physical Chemistry C, vol. 111, no. 22, pp. 8075-8079, 2007.

[16] C. C. Wang and J. Y. Ying, "Sol-gel synthesis and hydrothermal processing of anatase and rutile titania nanocrystals," Chemistry of Materials, vol. 11, no. 11, pp. 3113-3120, 1999.

[17] G. K. Mor, K. Shankar, M. Paulose, O. K. Varghese, and C. A. Grimes, "Use of highly-ordered $\mathrm{TiO}_{2}$ nanotube arrays in dyesensitized solar cells," Nano Letters, vol. 6, no. 2, pp. 215-218, 2006.

[18] K.-P. Wang and H. Teng, "Structure-intact $\mathrm{TiO}_{2}$ nanoparticles for efficient electron transport in dye-sensitized solar cells," Applied Physics Letters, vol. 91, no. 17, Article ID 173102, 2007.

[19] Y. H. Su, W. H. Lai, L. G. Teoh, M. H. Hon, and J. L. Huang, "Layer-by-layer Au nanoparticles as a Schottky barrier in a water-based dye-sensitized solar cell," Applied Physics A, vol. 88, no. 1, pp. 173-178, 2007.

[20] P. M. Sommeling, B. C. O’Regan, R. R. Haswell et al., "Influence of a $\mathrm{TiCl}_{4}$ post-treatment on nanocrystalline $\mathrm{TiO}_{2}$ films in dye-sensitized solar cells," Journal of Physical Chemistry B, vol. 110, no. 39, pp. 19191-19197, 2006.

[21] I. Bedja, P. V. Kamat, X. Hua, A. G. Lappin, and S. Hotchandani, "Photosensitization of nanocrystalline $\mathrm{ZnO}$ films by bis $\left(2,2^{\prime}\right.$-bipyridine $)\left(2,2^{\prime}\right.$-bipyridine- $4,4^{\prime}$-dicarboxylic acid)ruthenium(II)," Langmuir, vol. 13, no. 8, pp. 23982403, 1997. 

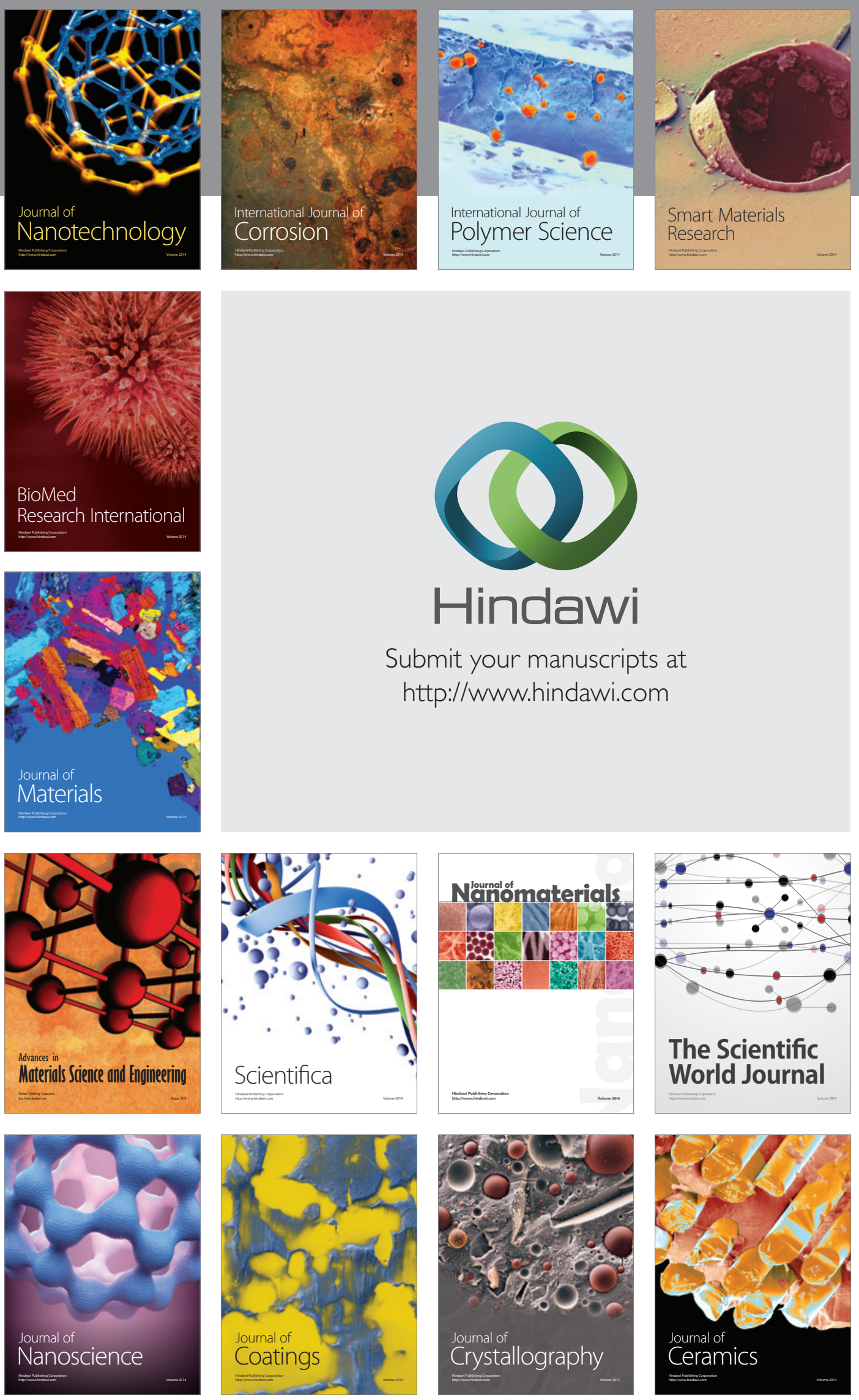

The Scientific World Journal

Submit your manuscripts at

http://www.hindawi.com

\section{World Journal}

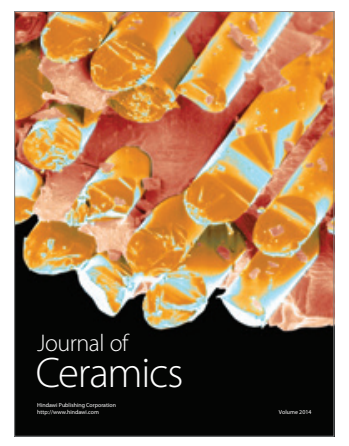

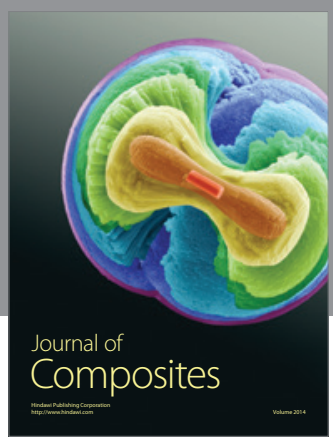
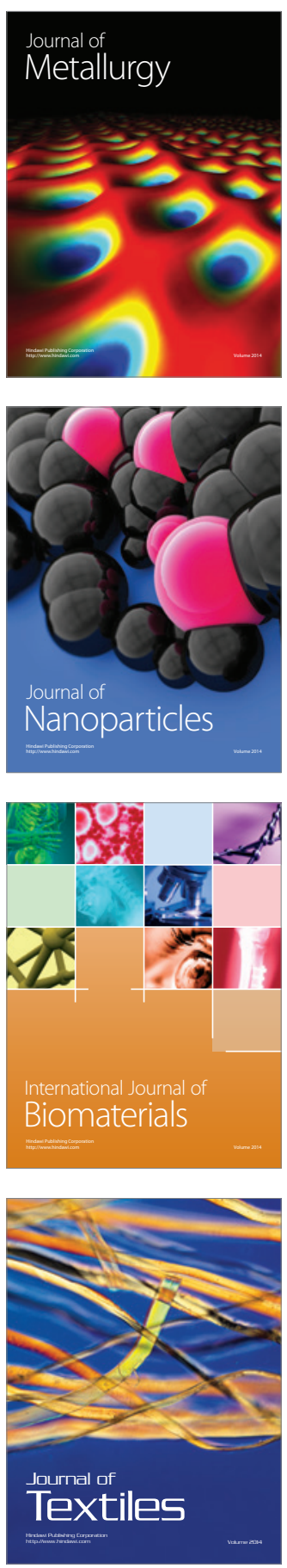